\title{
A High Resolution SEM Study of the Effects Supplementation Different Ratio Of $n-6: n-3$ on the Endometrial Pregnant Rat
}

\author{
Amira Kassem \\ Genetic resource center, Faculty of Agriculture, Sana'a University, Republic of Yemen \\ E-mail: amirabarialika@gmail.com
}

Md Zuki Abu Bakar

Department of Veterinary Preclinical Sciences

Faculty of Veterinary Medicine, Universiti Putra Malaysia 43400 UPM Serdang, Selangor, Malaysia

Goh Yong Meng

Department of Veterinary Preclinical Sciences

Faculty of Veterinary Medicine, Universiti Putra Malaysia 43400 UPM Serdang, Selangor, Malaysia

Noordin Mohamed Mustapha

Department of Pathology and Microbiology Veterinary

Faculty of Veterinary Medicine, Universiti Putra Malaysia

43400 UPM Serdang, Selangor, Malaysia. 
Received: July 29, 2013 Accepted: August 14, 2013 Published: October 26, 2016

doi:10.5296/jbls.v8i1.4058

URL: http://dx.doi.org/10.5296/ jbls.v8i1.4058

\begin{abstract}
This study, therefore, aims to investigate the effects of dietary fatty acids on endometrial pinopode expression. Twenty eight rats were randomly divided into four groups (seven rat per treatment). Treatment diets were rat chow only control diet ( con ), rat chow containing $0.9 \mathrm{ml}$ soybean oil $(\mathrm{SO})+0.9 \mathrm{ml}$ cod liver oil (CLO) the ratio 1:1, rat chow added with 1.5 $\mathrm{ml} \mathrm{SO}+0.3 \mathrm{ml} \mathrm{CLO}$ the ratio 6:1 and rat chow added with $1.74 \mathrm{ml} \mathrm{SO}+0.06 \mathrm{ml}$ CLO the ratio 30:1 ,feeds of $15 \mathrm{~g} /$ day were given and water was available ad libitum .. The endometrial samples were evaluated under SEM. developing pinopodes were seen during increasing progesterone concentrations especially in Diet 1:1 group, and regressing pinopodes were found with decreasing progesterone in Diet 30:1 groups. In both Diet 1:1 treated and control animals, on days 15 of pregnancy, scanning electron micros copy revealed the microvilli of the uterine epithelial cells in the treated animals were more dense than those in the Diet 30:1 treated animals.
\end{abstract}

Keywords: Endometrium, pinopodes, progesterone, scanning electron microscopy.

\title{
1. Introduction
}

Uterus is the major female reproductive organ of most mammals, including human. On one end, the cervix opens into the vagina, while on the other is connected to both sides of the fallopian tubes. The main function of uterus is to accept a fertilized ovum which then will be implanted into the endometrium, and derive nourishment from blood vessels which are developed exclusively for this purpose (Fawcett and Jensh, 2002). The rat has a duplex uterus: the uterine horns lie in the dorsal abdominal cavity, the uterine body and vagina lie between the dorsally located rectum and ventrally located urinary bladder. The wall is composed of mucosa (endometrium), two smooth muscle layers (myometrium) and adventitia. The single row of columnar epithelium lining the mucosa forms uterine glands projecting into the endometrial propria (stroma) (Krinke, 2000).

The mammalian uterus is a very dynamic organ which is capable of considerable physical and morphological changes in response to the changing in reproductive cycle. In some species, for example, in the rat and primates including humans, the interaction of the blastocyst with the uterine epithelium initiates decidualization of the endometrium which is characterized by increased vascular permeability and a highly ordered wave of stromal cell differentiation. The myometrium is maintained in a quiescent state until the onset of labor (Jain et al., 2000).

Maintenance of pregnancy throughout gestation is hormonally regulated by the coordinated actions of estrogen and progesterone. Progesterone maintains the uterus in a quiescent state and appears to be the principal hormone required for maintenance of a conceptus supportive environment in all species (Bazer et al., 1989; Keyes and Wiltbank, 1988). However, there is 
a considerable interspecies variation in the source of this hormone throughout gestation. In the rat, progesterone secretion is primarily ovarian, but is supplemented by the placenta in late gestation (Thorburn and Challis, 1979). The aim of the current study was to assess the expression of endometrial pinopodes by scanning electron microscopy may reflect in hormone-controlled.

\section{Materials and Methods}

\subsection{Animals}

The study was approved by the Animal Care and Use Committee, Faculty of Veterinary Medicine, Universiti Putra Malaysia (UPM/FPV/PS/3.2.1.551/AUP-R23).. Twenty eight female, two month old Sprague Dawley $(240 \pm 20 \mathrm{~g})$ rats were used in this experiment. Animals were maintained in temperature controlled quarters at $23{ }^{\circ} \mathrm{C}$, with a 12-h light-dark cycle and received rat pellet and water ad libitum. Daily vaginal smears of each animal were used to confirm normal cycling and for the identification of the pro-oestrous stage of the oestrous cycle, for purposes of mating.. Pregnancy was achieved by overnight mating of pro-oestrous females with males of proven fertility. The presence of a vaginal plug, as well as sperm in the vaginal smear taken the following morning, was used to confirm successful mating and this was designated as day 0 of pregnancy.

\subsection{Treatment Regime}

In order to examine changes in uterine progesterone effects in response to the supplementation unsaturated fatty acids to the diet, The four treatment groups included the rats fed with standard chow diet supplemented with $50 \% \mathrm{w} / \mathrm{w}$ soybean oil and $50 \% \mathrm{w} / \mathrm{w}$ cod liver oil (1:1) (diet 1), rats fed with standard chow diet supplemented with $84 \%$ w/w soybean oil and 16\% w/w cod liver oil (6:1) (diet 2), rats fed with standard chow diet supplemented with $96 \% \mathrm{w} / \mathrm{w}$ soybean oil and $4 \% \mathrm{w} / \mathrm{w}$ cod liver oil (30:1) (diet 3), and rats fed with only standard rat chow diet and acted as the control (diet 4). Tissue was taken on day 15 of pregnancy.

\subsection{Tissue Preparation for Scanning Electron Microscopy (SEM)}

The microvilli density, small secretion and pinopodes cell morphology in the endometrium were examined using scanning electron microscopy (SEM). Samples of uterine tissue were fixed in $4 \%$ glutaraldehyde buffered solution ( $\mathrm{PH} \mathrm{7.3).} \mathrm{The} \mathrm{samples} \mathrm{were} \mathrm{then} \mathrm{washed} 3$ times in $0.1 \mathrm{M}$ sodium cacodylate buffer for 10 minutes each and then post fixed for 2 hours with $1 \%$ osmium tetroxide (OsO4). The fixed samples were rinsed and dehydrated in a graded acetone series. The samples were then dried by critical point dryer (CPD 030 Bal-TEC, Swaziland) and were coated with gold (SEM Coating Unit E 5100, Parlon Equipment England). The samples were then viewed under JSM 6400 scanning electron microscope.

\subsection{Data Collection}

Digital images were collected of secondary electron microscopy images using magnifications: $\times 2000$. 


\subsection{Morphological Analysis of Tissue}

Table 1 shows the three luminal epithelial surface characteristics and their descriptions used in the morphological analysis of the fatty acids treated and normal pregnant uterine tissue. For analysis, the most representative area of each tissue sample was photographed and studied. Three representative micrographs were taken from each animal's tissue sample. For the morphological analysis of the secretions and Pinopodes, the $\times 20,000$ micrographs from each animal were used.

Table 1. Description of the scoring system used to analyse the surface epithelial features from SEM micrographs of the luminal epithelium of the endometrium at day 15 of pregnancy of the control animals and animals treated with different ratio n-6:n3 fatty acids at day 15 of pregnancy .

\begin{tabular}{|l|l|l|}
\hline \multicolumn{2}{|l|}{ Epithelial characteristics } & Scoring system \\
\hline 1 & Microvilli density & $\begin{array}{l}\text { The relative number of microvilli seen per cell } \\
(1, \text { sparse; } 2, \text { medium density; } 3, \text { dense })\end{array}$ \\
\hline 2 & Small secretions & $\begin{array}{l}\text { The number of small secretory droplets seen within the field } \\
(0, \text { none; } 1, \text { some; } 2, \text { many) }\end{array}$ \\
\hline 3 & Large surface protrusions & $\begin{array}{l}\text { The number of large protrusions seen on the cell surface }(0, \\
\text { none; } 1, \text { some; } 2, \text { many) }\end{array}$ \\
\hline
\end{tabular}

Seven uterine epithelial cell characteristics were analysed and scored according to the scoring system described.

\subsection{Statistical Analysis}

Once the data was scored according to the scoring system (Adams et al., 2004) summarised in Table 1, descriptive statistical analysis (Huck et al., 1974) was performed using JMP 5.0.1 statistical program (version 3.1.6.2; SAS Institute, Cary, NC). The median and quartile (25\% and $75 \%$ ) values were obtained and data expressed as median \pm quartiles.

For each section, 7 fields were taken, and the measurements for each field were averaged to give a mean score and standard deviation for that section. Kruskal-Wallis non-parametric one-way analysis variance (ANOVA) was used

\section{Results}

Table 2 provides an overview of the results obtained from the morphological analysis of the electron micrographs with regards to each of the 3 characteristics used for comparison. 


\section{Macrothink}

Table 2. The results from the control and treated animals, killed on days 15 of pregnancy.

\begin{tabular}{|l|l|l|l|}
\hline Treatment & Microvilli density & Small secretions & Cell surface protrusions \\
\hline Diet $1: 1$ & Medium/dense & Some/many & Many \\
\hline Diet 6:1 & Medium & Some/many & Some \\
\hline Diet 30:1 & Sparse/medium & Some & None/some \\
\hline Diet control & Medium/dense & Some/many & Many \\
\hline
\end{tabular}

The scanning electron micrographs were morphologically analysed by a scoring system described in Table 1. The average score was taken for each group of animals and then matched to the scoring system in Table 1 to define each observed characteristic.

The microvilli of endometrium in both the control group (Figure 1) and Diet 6:1 group (Figure 1) rats on day 15 of pregnancy were generally short, while not much variation was seen in the microvilli length for Diet 6:1 group and Diet 30:1group (Figure 2). However, variation was observed in the microvilli density (Figure 1). In the control group, the microvilli were observed to have medium to dense (Figure 1), while in the Diet 30:1group, the microvilli were sparse with low density and the epithelial surfaces were flat with very low number of microvilli (Figures 2). It appeared that low ratio of $n 6: n 3$ (Diet 1:1) increased the density of the microvilli of the uterine epithelial cells.

The most interesting results found in this experiment were the small, round and smooth secretory droplets that were seen near the periphery of the uterine epithelial cells in the Diet 1:1 and Diet 6:1 group on day 15 of pregnancy, respectively. On the same day of pregnancy, in the treated animals of Diet 6:1 group and control group , many of these small secretions were observed in the uterine epithelial cells, respectively.

Pinopodes were observed covering, developing and bulges without or with only some wrinkles in the surface of the luminal epithelium of the endometrium in the rats of control group and Diet 6:1 group as shown Figures 1, respectively. However, they became slightly less, regressing and started to disappear in the Diet 30:1group (Figure 2). Developed pinopodes were larger, bulges without wrinkles in the rats of Diet 6:1 group (Figure 2). The results showed that the appearance of these pinopodes was directly related to the different ratio of $n 6: n 3$ fatty acids supplementation diets 


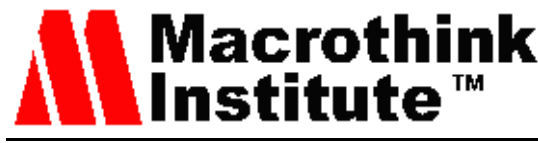
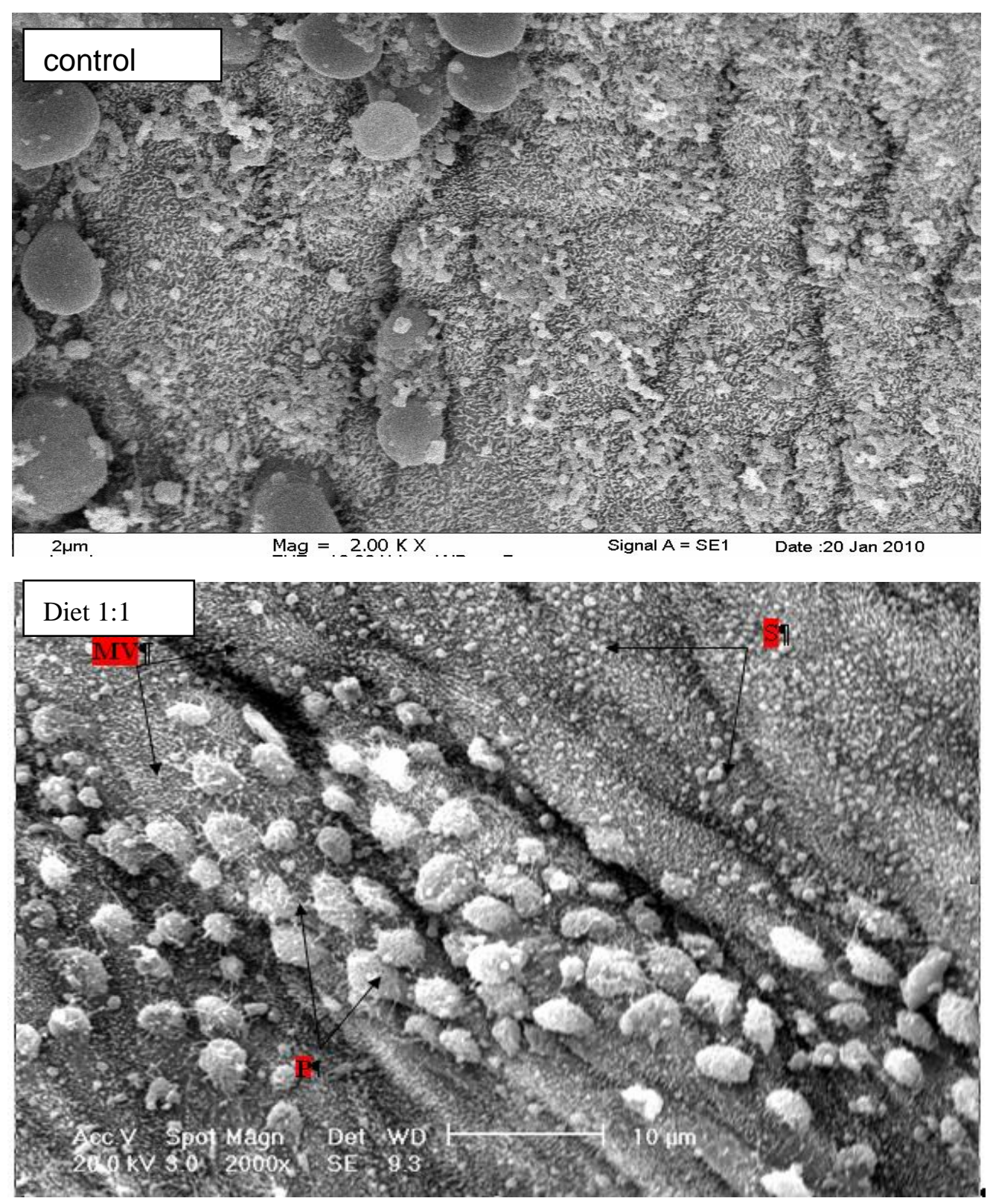

Figure 1. Scanning electron micrograph of the uterine epithelial surface on day 15 of gestation in rat of control group. Note that microvilli (MV) of endometrium are become generally short and clearly seen with medium to dense. The small secretions (S) appear small, round and smooth secretory droplets and the pinopodes $(\mathrm{P})$ are observed covering, developing and bulges without or with some wrinkles in the surface of the luminal epithelium of the endometrium. And the Diet 1:1 group. Note that the MV of endometrium are generally short and clearly seen with high density and numerous in number. The small secretions are small, round and smooth and the (P) are observed covering, developing and bulges without or with some wrinkles on the surface of luminal epithelium of the endometrium. x2000 


\section{MInstitute ${ }_{\text {Mnk }}^{\text {Macrothink }}$}
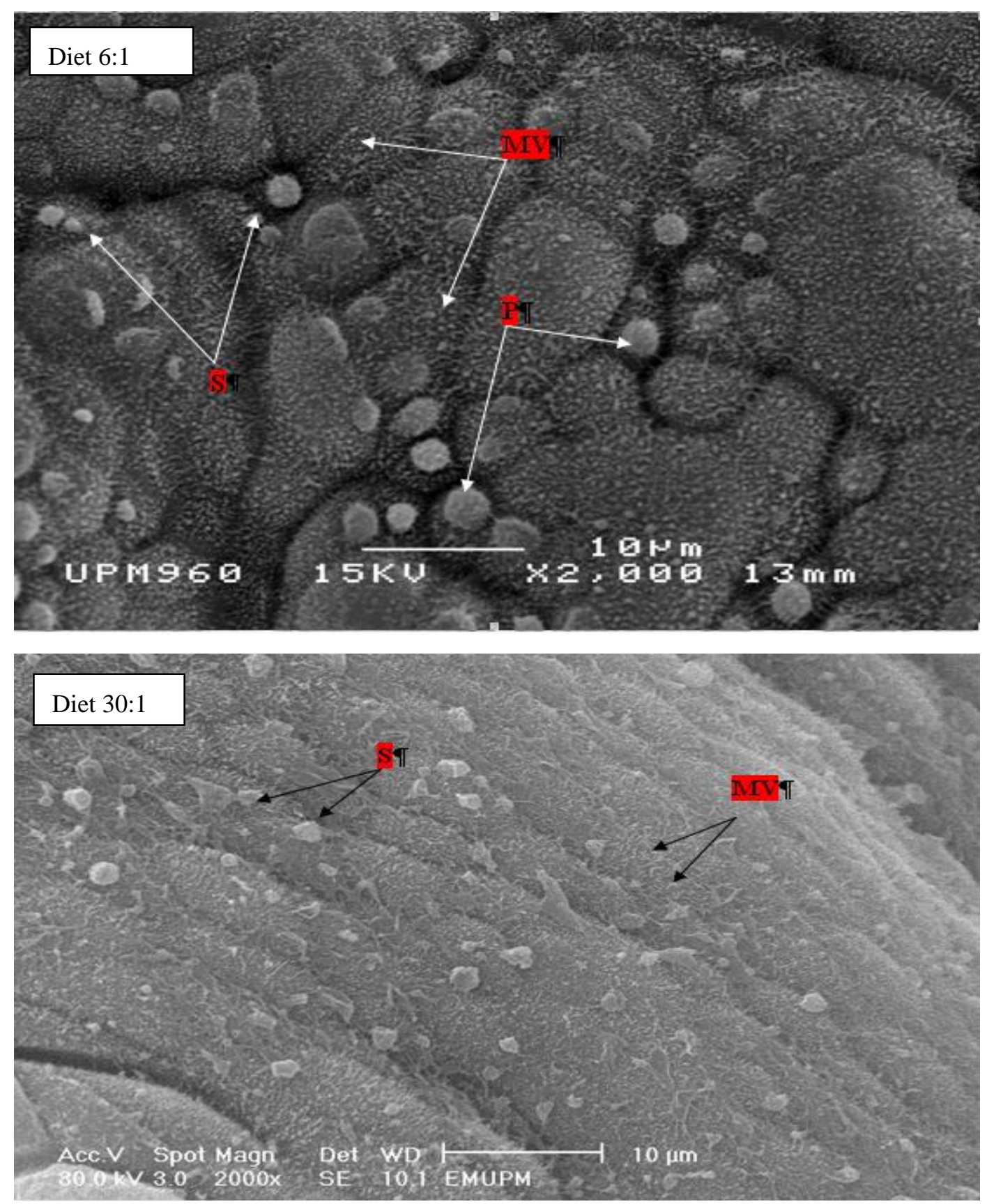

Figure 2. Scanning electron micrograph of the uterine epithelial surface on day 15 of gestation in rat of Diet 6:1 group . Note that the microvilli (MV) of endometrium are not much variation as compared to other groups. The small secretions (S) appeare small and the pinopodes (P) are developed, larger, bulges without wrinkles and less covering the surface of

luminal epithelium of the endometrium.And the Diet 30:1 group. Note that the MV of endometrium are sparse and are not clearly seen with low density and very low number. The small secretions appear small and the $\mathrm{p}$ become slightly less, regressing and start to disappear in the surface of luminal epithelium of the endometrium. x2000 


\section{Discussion}

In the present study, morphometric assessment of the endometrium was performed to evaluate the histological alterations in the uterine endometrium under the influence of different ratios of $n 6: n 3$ fatty acids supplementation at the light microscopic level. The main aim of this experiment was to determine the endometrial changes in the pregnant rats treated with different ratios of $n 6: n 3$ fatty acids supplementation on day 15 of pregnancy. In theory, morphological alterations of the endometrium may affect the length of gestation and the growth of the embryo. Assessing the endometrial morphological parameters including glandular area, diameter and volume have been used to evaluate the changes in the structure and function of endometrial glands more accurately (Wahab et al., 1999)

In rodents, the process of implantation involves complex interactions and requires a very precise coordination between the establishment of uterine receptivity and the blastocyst activation (Chakraborty et al., 1996). This process is primarily dependent on the concerted effects of sex steroids (Salazar and Calzada, 2006). At the beginning of pregnancy, preovulatory ovarian E2 induces epithelial cell proliferation (Given and Enders, 1980). In this study the uterine receptivity may be influenced by changes of the circulating levels of estradiol. On the other hand, progesterone is needed for the development of important cell structures, such as pinopodes and microvilli in rodent endometrial (Panzan et al., 2006). The scanning electron microscopic examinations showed that in comparison of apical membrane of all groups, the microvilli were present; although the number of these structures had some variation. However, in rats fed high ratio of $n-6: n-3$ fatty acids supplementation (Diet 30:1), the microvilli were disappeared and in contrast, they were seen in the uterine epithelial cells in rats fed low ration of $n-6: n-3$ (Diet 1:1 group). The SEM examinations also revealed that the projections on the surface were typical pinopodes, which are the implantation marker. It seems that in these groups, the microvilli decreased in number and length. Similar finding was observed by Stavreus-Evers et al. (2001). The estrogen causes an increase in length and number of microvilli including the amount of secretory droplets while the progesterone affects the uterine epithelial cell flattening and decrease the shortening of microvilli in bovine and other species (Fathalla, 1971). This fact may explain why there was a reduction in the number of implantations in the group of low ratio of $n-6: n-3$ faty acids supplementation (Diet 30:1 group). The interactions between diet and circulating steroid hormone concentrations are complex. The high ratio of $n-6: n-3$ in Diet 3 group increased plasma estrogen concentrations relative to the other dietary treatments and decreased plasma progesterone concentrations relative to the other dietary treatments. Supplementation of high ratio of $n 6: n 3$ as in the Diet 3 group decreased concentration of circulating progesterone (Milvae et al., 1986). The morphological changes in endometrial cells are controlled by steroid hormones (Rider et al., 1998). Thus, as the concentration of progesterone increases, this proliferative effect seems to be higher (Fazleabas et al., 1999).

Progesterone plays a role in preparing the female reproductive tract for conception and implantation of the embryo and in maintaining the uterine environment during growth and development of the fetus, placenta and fetal membranes until parturition. In the current study, developing pinopodes were seen during increasing progesterone concentrations especially in 


\section{Ml Macrothink}

Journal of Biology and Life Science

ISSN 2157-6076

2017, Vol. 8, No. 1

Diet 1:1 group, and regressing pinopodes were found with decreasing progesterone in Diet 30:1 groups. In contrast, there are some reports on a high incidence of dysfunction of endometrium under high physiological level of estrogen and progesterone. The high level of these hormones could affect the endometrial receptivity (Kramer and De Wet, 1994; Kramer et al., 1993; Valbuena et al., 1999). Progesterone is needed for the development of pinopodes in rodent endometrial (Singtripop et al., 1991; Singh et al., 1996). Thus, embryo implantation might be related to the number of pinopodes and the circulating progesterone levels (Rossi et al., 2002). In this study, development of pinopodes and microvili followed the progesterone level, but absolute concentrations of progesterone and pinopode development were correlated. The presence and development of pinopodes mainly depend on the ovarian hormones, especially progesterone (Singh et al., 1996), while high concentration of estrogen interfere normal formation of pinopodes (Martel et al., 1991; Simon et al., 1997).

\section{Conclusion}

The findings of this experiment suggest that supplementation of fatty acids with different ratio of $n-6: n-3$ could change the endometrial morphology during the pregnancy. The tissue morphological characteristics changes was significantly different in high ratio of $n-6: n-3$ fatty acids as compared to the low ratio of $n-6: n-3$ fatty acids .

\section{References}

Bazer, F. W., Vallet, J. L., Harney, J. P., Gross, T. S., \& Thatcher, W. W. (1989). Comparative aspects of maternal recognition of pregnancy between sheep and pigs. Journal of Reproduction and Fertility. Supplement, 37, 85-89.

Chakraborty, I., Das, S. K., Wang, J., \& Dey, S. K. (1996). Developmental expression of the cyclo-oxygenase-1 and cyclo-oxygenase- 2 genes in the peri-implantation mouse uterus and their differential regulation by the blastocyst and ovarian steroids. J Mol Endocrinol, 16(2), 107-122.

Dursun, A., Sendag, F., Terek, M. C., Yilmaz, H., Oztekin, K., Baka, M., \& Tanyalcin, T. (2004). Morphometric changes in the endometrium and serum leptin levels during the implantation period of the embryo in the rat in response to exogenous ovarian stimulation. Fertility and Sterility, 82 Suppl 3, 1121-1126.

Fathalla, M. F. (1971). Incessant ovulation-a factor in ovarian neoplasia? Lancet 2:163

Fazleabas, A. T., Donnelly, K. M., Srinivasan, S., Fortman, J. D., \& Miller, J. B. (1999). Modulation of the baboon (Papio anubis) uterine endometrium by chorionic gonadotrophin during the period of uterine receptivity. Proceedings of the National Academy of Sciences of the United States of America, 96(5), 2543-2548.

Fawcett, D. W., \& Jensh, R. P. (2002). Female Reproductive System.In: Bloom \& Fawcett's Concise Histology. 2nd Ed.London, Arnold Publishers. pp.283-96.

Given, R. L., \& Enders, A. C. (1980). Mouse uterine glands during the peri-implantation period: Fine structure. American Journal of Anatomy, 157(2), 169-179. 
Jain, V., Saade, G. R., \& Garfield, R. E. (2000). Structure and function of the myometrium. In A Functional View of Smooth Muscle, 8, 215-246.

Kramer, B., Magan, A., \& De Wet, G. (1993). Hyperstimulation affects vascular permeablility at implantation sites in the rat endometrium. J Assist Reprod Gen, 10, 163-168.

Kramer, B., \& De Wet, G. (1994). Exogenous gonadotropin administration affects the glycocalyx of rat endometrial epithelial cells during the period of implantation. $J$ Assist Reprod Gen, 11, 504-509.

Keyes, P. L., \& Wiltbank, M. C .(1988). Endocrine Regulation of the Corpus Luteum. Annual Review of Physiology, 50(1), 465-482.

Krinke, G. (2000). The laboratory rat. Academic Press.

Martel, D, Monier, M. N., \& Roche, D. (1991). Psychyos A. Hormonal control of pinopode formation at the uterine luminal surface. Hum Reprod., 6,597-603.

Milvae, R. A., Alila, H. W., \& Hansel, W. (1986). Involvement of lipoxygenase products of arachidonic acid metabolism in bovine luteal function. Biology of Reproduction, 35(5), 1210-1215.

Nikas, G., Drakakis, P., Loutradis, D., Mara-Skoufari, C., Koumantakis, E., Michalas, S., \& Psychoyos, A. (1995). Uterine pinopodes as markers of the 'nidation window' in cycling women receiving exogenous oestradiol and progesterone. Human Reproduction (Oxford, England), 10(5), 1208-1213.

Panzan, M. Q., Júnior, J. M. S., da Motta, E. L. A., Haapalainen, E. F., de Jesus Simões, M., Baptista, H. A., \& Haidar, M. A. (2006). Metoclopramide-induced hyperprolactinaemia caused marked decline in pinopodes and pregnancy rates in mice. Human Reproduction (Oxford, England), 21(10), 2514-2520.

Rider, V, Kimler, B. D., \& Justice, W. M. (1998). Progesterone-growth factor interactions in uterine stromal cells. Biology of Reproduction, 59, 464-469.

Roberts, D. K., Parmley, T. H., Walker, N. J., \& Horbelt, D. V. (1992). Ultrastructure of the microvasculature in the human endometrium throughout the normal menstrual cycle. American Journal of Obstetrics and Gynecology, 166(5), 1393-1406.

Rossi, A. G., Soares Jr., J. M., Motta, E. L., Sim\&otilde;es, M. J., Oliveira-Filho, R. M., Haidar, M. A., \& Rodrigues de Lima, G. (2002). Metoclopramide-Induced Hyperprolactinemia Affects Mouse Endometrial Morphology. Gynecologic and Obstetric Investigation, 54(4), 185-190.

Stavreus-Evers, A., Nikas G., Sahlin, L., Eriksson, H., \& Landgren, B. M. (2001). Formation of pinopodes in human endometrium is associated with the concentrations of progesterone and progesterone receptors. Fertil Steril, 76, 782-791 
Simoni, M., Gromoll, J., \& Nieschlag, E. (1997). The Follicle-Stimulating Hormone Receptor: Biochemistry, Molecular Biology, Physiology, and Pathophysiology. Endocr Rev, 18(6), 739-773.

Singtripop, T., Mori, T., Park, M. K., Sakamoto, S., \& Kawashima, S. (1991). Development of uterine adenomyosis after treatment with dopamine antagonists in mice. Life Sciences, 49(3), 201-206.

Singh, M., Chauhan, S., Trivedi, R., Maitra, S., \& Kamboj, V. (1996). Correlation of pinopod development on uterine luminal epithelial surface with hormonal events and endometrial sensitivity in rat. Eur J Endocrinol, 135(1), 107-117.

Thorburng, G., \& Challis, J. R. (1979). Endocrine control of parturition. Physiological Reviews, 59, 863-918.

Valbuena, D, Jasper, M, Remon, J, Pellicer, A, \& Sima, C.(1999). Ovarian stimulation and endometrial receptivity. Hum Reprod, 1, 2107-2111.

Wahab, M., Thompson, J., Hamid, B., Deen, S., \& Al-Azzawi, F. (1999). Endometrial histomorphometry of trimegestone-based sequential hormone replacement therapy: a weighted comparison with the endometrium of the natural cycle. Human Reproduction (Oxford, England), 14(10), 2609-2618.

\section{Copyright Disclaimer}

Copyright for this article is retained by the author(s), with first publication rights granted to the journal.

This is an open-access article distributed under the terms and conditions of the Creative Commons Attribution license (http://creativecommons.org/licenses/by/3.0/). 